\title{
Iodent Germplasm Source Material Selection in Development of Maize Hybrids for the Steppe Zone of Ukraine
}

\author{
B. V. Dziubetskyi ${ }^{1}$, V. Yu. Cherchel $^{1}$, O. V. Abelmasov ${ }^{1}$, V. V. Semenova ${ }^{2}$, M. M. \\ Tagantsova $^{3}$
}

\author{
${ }^{1}$ SE Institute of Grain Crops NAAS of Ukraine, 14. Volodymyr Vernadskyi Street, Dnipro, Ukraine \\ ${ }^{2}$ SPFE "Company "Mais" Ukraine \\ ${ }^{3}$ Ukrainian Institute for Plant Variety Examination, Ukraine
}

B. V. Dziubetskyi: https://orcid.org/0000-0001-9637-6392

V. Yu. Cherchel: https://orcid.org/0000-0002-0429-4961

O. V. Abelmasov: https://orcid.org/0000-0001-6595-0929

V. V. Semenova: https://orcid.org/ 0000-0002-1511-9376

M. M. Tagantsova: https://orcid.org/0000-0003-3737-6477

E-mail: vlad cherch@ukr.net

Received 16.01.2020 Accepted 07.02.2020

\begin{abstract}
The aim of the study: Evaluation of sister hybrids obtained on the basis of early maturity Iodent germplasm inbred lines (FAO 180-250) as a source material for the development of new inbred lines and evaluation of this material's main breeding qualities as well as of level of hypothetical heterosis in sister crosses and their polymorphism as an integral part of the breeding cycle. Methods: Field method, mathematical-statistical method.

Results: The studies investigated sister hybrids obtained by crossing of 8 precocious Iodent germplasm inbred lines, their combining ability for "grain yield" trait and determined whether they can be used as a source material for the synthesis of new homozygous inbred lines. The results of the evaluation of sister hybrids and their testcrosses on the basic economically valuable traits are presented. According to research results in 2013-2015, it was found that sister hybrids with the least variable grain yields by years of research were obtained from the crossing of DK1274 and DK237 inbred lines. The calculations of the correlation coefficients between hypothetical heterosis and genetic distances revealed no significant correlation between them ( $r=0.118-0.359)$ as well as between the yield of sister hybrids and genetic distances $(r=0.167-0.351)$. It was found that the least variable indicators of grain yield for the years of research were noted in sister hybrids obtained on the basis of source inbred lines with the most stable manifestation of this indicator $(r=0.714)$. Sister hybrids were noted, which had effects of general combining ability at class 2 , regardless of study conditions (DK216 $\times$ DK213, DK237 $\times$ DK1274, DK714/195 $\times$ DK216), indicating the stability of genotype response to growing conditions.

Conclusion: The evaluation of 8 precocious constant Iodent germplasm inbred lines on breeding traits revealed the best of them (DK555 and DK1274) in combining ability compared to the DK744 control inbred line. Significant influence of the conditions of research years on all the traits studied was noted. The study of sister hybrids has revealed forms with a significant manifestation of hypothetical heterosis. It was the highest on average in crosses of inbred lines DK234 (137.0\%), DK714/195 (122.7\%) and DK216 (101.1\%), and the smallest in hybrids with inbred lines DK555 (58.5\%), DK1274 (65.8\%) and DK744 (75.0\%). Sister combinations with DK1274 and DK237 inbred lines were characterized by the highest yield stability over the years of study. In determining genetic distances, the most genetically similar inbred lines DK744 (0.136) and DK234 (0.197) to inbred line 207 (P165), which is the classic representative of the Iodent germplasm, are noted.
\end{abstract}

Keywords: Maize; Source inbred lines; Iodent; Sister hybrids; General combining ability; Hypothetical heterosis; Genetic distances

\section{Introduction}

Breeding of maize (Zea mays L.) hybrids of different maturity groups is based on the use of the most common germplasms such as Lancaster, Reid (SSS), Iodent, Lacaune. Self-pollinated lines obtained on their basis at crossing with each other, as a rule, provide high level of heterosis, which is the key to successful synthesis of new high-performance hybrids. Therefore, most breeding establishments in their programs foresee a continuous improvement of the source material derived from basic germplasms on various economically valuable traits.

\section{Status of problem study}

Development of high-yielding hybrids is first and foremost a selection of parent pairs with high combining ability. The results of the evaluation of the combining ability of the breeding material allow us to focus on the selection of the most promising forms, and 
more purposefully select the components to obtain new hybrids and, ultimately, more successfully develop highly heterozygous hybrid combinations (Chilashvili, 2015). The implementation of the program of synthesis of new source material in the system of cumulative breeding involves the development of special hybrid combinations with the participation of the best elite inbred lines of maize (Kostyuchenko, 1992: Fedko, 2009: Haidash, 2016). The small number of basic elite inbred lines makes it possible to develop a large quantity of different hybrid combinations that respond differently to self-pollination (Halechko, 2007). To optimize the whole sample of inbred generations, early testing of S1-3 generations of self-pollination is used, but with such an assessment of their combining ability, the volume of research is significantly increased as well as the costs of trials for testcrosses (Kostyuchenko, 1992: Halechko, 2007). It is noted that hybrid combinations with high combining ability by "grain yield" trait allow to obtain on their basis the best self-pollinated lines by this index (Domashnev, 1992: Dzyubetskiy, 2002: Dziubetskyi, 2001). The level of combining ability of the source material by the basic economically valuable traits is the main criterion when evaluating new breeding material. It is known that adverse environmental factors during the critical periods of maize organogenesis lead to significant variability in estimates of general combining ability (GCA) and specific combining ability (SCA) (Dziubetskyi, 2011: Cherchel, 2018).

\section{The aim of the study}

Investigation of sister hybrids obtained on the basis of early maturity Iodent germplasm inbred lines (FAO 180-250) as source material for the breeding of new self-pollinated lines, and its evaluation by major breeding traits, the level of hypothetical heterosis in sister crosses and their polymorphism as an integral part of breeding cycle.

\section{Research Methodology}

The researches were carried out in the experimental farm "Dnipro" of the State Enterprise Institute of Grain Crops of the National Academy of Agrarian Sciences of Ukraine in 2013-2015. Phenological observations and biometric measurements were performed in breeding and control nurseries. The accounting area of the plots was $5 \mathrm{~m}^{2}$, the repetition was triple. Plant density was 60 thousand plants/ha. The scheme of carrying out researches corresponded to the recommendations set forth in the Methodology of the state variety testing of crops (Vovkodava, 2001) and Methodical recommendations on field and laboratory study of genetic resources of maize (Hurieva, 2003). The estimation of the parameters of the combining ability in the system of incomplete testcrosses was carried out according to the methodology of G. K. Dremlyuk, V. F. Gerasimenko (Dremlyuk, 1991) on a personal computer using special applications. The source material included 8 precocious Iodent germplasm inbred lines, developed by the SE Institute of Grain Crops of NAAS of Ukraine: DK1274, DK213, DK216, DK234, DK237, DK555, DK714/195 and DK744. For control we used the inbred line DK744, which is a part of 9 hybrids with FAO 180 - 330 developed by the SE Institute of Grain Crops of NAAS, listed in the State Register of Plant Varieties of Ukraine. During their diallelic crossing, 28 sister hybrids were obtained, which were considered as the source material for the development of new precocious inbred lines.

Four inbred lines - testers belonging to different germplasms - DK247 (Mixed), DK296 (Lancaster), DK272 (BSSS $\times$ Lacaune), DK951 (BSSS), were used to determine the combining ability of inbred lines and hybrids. The checks for the trials of testcrosses were hybrids: early maturity - Dniprovsky $181 \mathrm{CV}$, middle-early - Orzhitsa 237MV and medium maturity - Solonyansky $298 \mathrm{CV}$.

Weather conditions during the years of research were contrasting, which on the one hand made it possible to carry out the correct differentiation of the studied genotypes by resistance to abiotic factors, and on the other, created some problems during the breeding procedures in pollination period. The most favorable conditions for the vegetation of maize plants in terms of moisture content and temperature conditions occurred in 2013. They were average in 2014-2015, but the second half of the both growing seasons was marked by a significant drought due to the high temperatures and low air humidity, especially during the period of grain formation, which negatively affected the yield level of all the studied forms.

\section{Results}

The research was aimed at development of a new source material for the subsequent breeding of maize hybrids (FAO 180-250), adapted to the stress conditions of the steppe zone of Ukraine with high yields, low grain moisture at harvest and a range of other economically valuable traits. In connection with this, the annual study of the tester hybrid combinations was first performed on the combining ability by the "grain yield" trait, and then their prospectivity as a source material for the synthesis of homozygous inbred lines was determined. It should be noted that if the entire volume of breeding hybrids obtained is aimed at self-pollination without first assessing combining ability, the control trial of the test crosses will be unnecessarily time consuming, and the efficiency of such an extended test will not benefit and may even impair the accuracy of the studies (Cherchel, 2018).

In 2010, eight precocious (FAO 180-240) source Iodent germplasm inbred lines were crossed using the diallelic scheme and 28 sister hybrids were obtained, which were self-pollinated in 2011 and 320 S1 families were selected. All source inbred lines, sister hybrids, and S1 families were tested with 4 testers and were sown in 2012 to evaluate test crosses and perform selection for economically valuable traits. Almost $75 \%$ were eliminated among S1 families, primarily due to low drought and heat resistance, longer duration of period between seedlings appearance and flowering time of $50 \%$ of cobs than in the check inbred line DK744 for 3-4 days, as well as due to their non-compliance with other desirable traits. Three to five self-pollinations were performed on the plants of each family.

The study on grain yield of test crosses of sister hybrids showed that in favorable weather conditions in 2013, the average population index for grain yield was $7.36 \mathrm{t} / \mathrm{ha}$, which is at the level of check hybrid Orzhitsa $237 \mathrm{MV}$ and $1.21 \mathrm{t} / \mathrm{ha}$ more than the Dniprovsky $181 \mathrm{CV}$ hybrid yield, however, $1.23 \mathrm{t} /$ ha less than the medium maturity hybrid Soloniansky $298 \mathrm{CV}$. The coefficient of variation of grain yield in test crosses of sister hybrids was $V=11.13 \%$, with the difference between the limits $3.59 \mathrm{t} / \mathrm{ha}$. In terms of grain yield, $5.5 \%$ of the test crosses from the sister hybrid group exceeded the early-maturity hybrid check Dniprovskyi $181 \mathrm{CV}$ $53.8 \%$ of the testcrosses have exceeded the middle-early hybrid Orzhitsa $237 \mathrm{MV}$, and only $4.1 \%$ of testcrosses have exceeded the medium maturity hybrid check Soloniansky 298CV (Table 1 ).

The average grain yield of testcrosses of sister hybrids in 2014 was $5.92 \mathrm{t} /$ ha, which is higher than that of the Dniprovsky $181 \mathrm{CV}$ hybrid by $1.94 \mathrm{t} / \mathrm{ha}$ and at the level $(6.18 \mathrm{t} / \mathrm{ha})$ with the Orzhitsya $237 \mathrm{MV}$ hybrid. All testcross yields were inferior to the medium maturity hybrid Soloniansky 298CV yield (6.61 t/ha). The limits in the group were 4.22-7.13 t/ha. The coefficient of variation was equal to $V=9.72 \%$, which indicates a non-uniform reaction of the testcrosses to the growing conditions. In 2015 , the average grain yield of the testcrosses of the sister hybrids was $6.49 \mathrm{t} / \mathrm{ha}$, which is $12.0 \%$ lower than that of the Solonyansky $298 \mathrm{CV}$ hybrid and $6.9 \%$ lower compared to the Orzhitsya 237MV hybrid and almost on par with the Dniprovsky 181CV hybrid. Testcrosses were 
identified in which grain yield was significantly higher (by $0.14-0.72 \mathrm{t} / \mathrm{ha}$ ) than the grain yield of medium maturity hybrid check Solonyansky 298CV: (DK744 × DK555) × DK296 (9.21 t/ha), (DK216 × DK744) × DK296 (9.26 t/ha) and (DK237 × DK714/195) $\times$ DK951 (9.31 t/ha).

Table 1. Characterization of testcrosses of Iodent germplasm sister hybrids on the basis of "grain yield" and "grain moisture at harvest" traits.

\begin{tabular}{|c|c|c|c|c|c|c|c|}
\hline Parameters & & $\overline{\mathbf{x}} \pm \mathbf{s} \overline{\mathbf{x}}$ & $v, \%$ & $\begin{array}{l}\text { Lim } \\
\text { (min-max) }\end{array}$ & $\begin{array}{l}* 1^{\text {st }} \\
\text { check }\end{array}$ & $\begin{array}{l}2^{\text {nd }} \\
\text { check }\end{array}$ & $\begin{array}{l}3^{\text {rd }} \\
\text { check }\end{array}$ \\
\hline \multirow{4}{*}{ Grain yield, t/ha } & 2013 & $7.36 \pm 0,07$ & 11,13 & $5.72-9.31$ & 6.15 & 7.16 & 8.59 \\
\hline & 2014 & $5.92 \pm 0,04$ & 9.72 & $4.22-7.13$ & 4.88 & 6.18 & 6.61 \\
\hline & 2015 & $6.49 \pm 0,06$ & 9.12 & $5.10-7.64$ & 6.37 & 6.97 & 7.38 \\
\hline & $\bar{x} \pm s \bar{x}$ & $6.59 \pm 0,06$ & 9.99 & $5.01-8.03$ & 5.80 & 6.77 & 7.53 \\
\hline \multirow{4}{*}{$\begin{array}{l}\text { Grain moisture at } \\
\text { harvest, } \%\end{array}$} & 2013 & $21,0 \pm 0,12$ & 6.68 & $17.8-24.2$ & 22,5 & 23,6 & 25.9 \\
\hline & 2014 & $12,8 \pm 0,03$ & 2,85 & $12,1-14.0$ & 12,6 & 13,0 & 13,0 \\
\hline & 2015 & $11,0 \pm 0,04$ & 3,38 & $10,3-12,1$ & 11,2 & 11,0 & 12,4 \\
\hline & $\bar{x} \pm s \bar{x}$ & $15.0 \pm 0,06$ & 4.30 & $13,4-16.8$ & 15.4 & 15.9 & 17.1 \\
\hline
\end{tabular}

*1st check - Dniprovsky 181CV; 2nd check - Orzhitsya 237MV; 3rd check - Solonyansky $298 \mathrm{CV}$.

In the breeding of new maize hybrids, the "grain moisture content at harvest" trait is one of the defining factors, which in some sense is the criterion for the successful and efficient conduct of any breeding program. This is of particular importance given that post-harvesting grain processing is a very energy-intensive process and requires significant material costs (Dzyubetsky, 2013).

It should be noted that the genotypes whose grain is intensively losing moisture during maturation, often reduce the yield, especially in arid and hot conditions (Fedko, 2009). In testcrosses developed with the participation of sister hybrids, the average population moisture content of grain in 2013 was $21.0 \%$, which is significantly lower than in hybrids Dniprovsky $181 \mathrm{CV}$ (22.5\%), Orzhitsya 237MV (23.6\%) and Solonyansky 298CV (25.9\%). There were $23.5 \%$ of testcrosses in which grain moisture was significantly lower than the population average. In 2014. in testcrosses from sister hybrids, the average population moisture content of grain was lower by 39.0 relative percent than in 2013 and amounted to $12.8 \%$. The difference between the extreme values in the group was only $1.9 \%$. The coefficient of variation was negligible $(2.85 \%)$. The number of testcrosses with significantly lower grain moisture than in the Dniprovsky $181 \mathrm{CV}$ check hybrid was $18.4 \%$, and more than $70 \%$ of the testcrosses had this indicator significantly lower than Orzhitsa 237MV and Solonyansky 298CV checks. The average grain moisture content of testcrosses of sister hybrids in 2015 was $11.0 \%$, which is at the level with the mid-early hybrid Orzhitsya $237 \mathrm{MV}$ and significantly lower than in the medium maturity hybrid Solonyansky $298 \mathrm{CV}$. The coefficient of variation for testcrosses of this group has increased (V=3.38\%), but the difference between the limits decreased to $1.8 \%$ compared to 2014 . This indicator was lower than in check hybrid Orzhitsya $237 \mathrm{MV}$ in $45.9 \%$ of testcrosses, and for $64.7 \%$ of testcrosses it was lower than in the Dniprovsky $181 \mathrm{CV}$ hybrid.

For a clearer assessment of the testcrosses based on the indicators of GCA effects, the distribution of sister hybrids into conditional classes relative to the average of the experiment was performed. Concerning the trait "grain yield" it was shown that the same number of samples belonged to the 1st class in all the years of researches $-32 \%$. The maximum number of samples (29\%) attributed to class 3 was in 2013, and the minimum (18\%) was in 2015.

The number of samples studied pertaining to the 3rd class decreased from year to year (in 2013-29\%; $2014-25 \% ; 2015-18 \%$ ). However, the opposite tendency was observed in the case of sister hybrids, which according to the estimates of the GCA effects are classified as class 2, their number increased from 39\% in 2013 to $50 \%$ in 2015 .

Estimates of GCA effects on grain yields of sister hybrids indicate that they were consistently high in all three years of testing in sister hybrid DK237 $\times$ DK213, which had the highest GCA values $(0.34 ; 0.27 ; 0.71 \mathrm{t} /$ ha, respectively) and the smallest sum of classes-3 (Table 2). It should be noted that the hybrid DK744 × DK213 in 2013 had the value of estimate of the GCA effect - 0.06 $\mathrm{t} / \mathrm{ha}$, and under more arid conditions in 2014-2015 was assigned to the 1st class (0.61 and 0.24 t/ha, respectively).

The best-rated by GCA effects sister hybrids included source inbred lines, which were also characterized by high values of this indicator. The correlation coefficients of the estimates of the GCA effects between them were significant and were $r=0.51 ; 0.42$; 0.58 , respectively, for 2013-2015. The highest rates of GCA effects were in sister hybrids DK237 × DK213, DK744 × DK213, DK555 $\times$ DK213. Also hybrids that have had stable assessments of GCA effects at class 2 level over the years of research are distinguished: DK216 × DK213, DK237 × DK1274, DK714/195 × DK216.

With regard to SCA, its high variances in 2013 were noted in sister hybrids DK1274 × DK234, DK213 × DK234 and DK555 × DK213 (0.96; $0.91 ; 0.74$ respectively). In 2014-2015, the number of such samples decreased due to adverse weather conditions, high marks were observed only in stress-tolerant combinations. The most dynamic manifestation of SCA variances was observed in sister hybrids DK555 × DK234, DK555 × DK237 (0.00;0.16;0.57) and (0.18;0.57; 0.46), respectively, for 2013-2015.

Sister hybrids DK714/195 × DK237, DK237 × DK1274 and DK555 × DK237 had GCA estimates in 2014-2015 with negative values, indicating their instability under more extreme growing conditions. Sister hybrid DK714/195 × DK213 in 2013 had a negative value for the GCA estimate, but in the drier conditions of 2014-2015, it was assigned to class 1.

The distribution of sister hybrids according to the estimates of GCA effects for the "grain moisture at harvest" trait, indicated that the sum of their classes ranged from 5 to 7 . Relatively high values of GCA effects in 2013-2015 were in sister hybrids DK1274 $\times$ DK213, DK237 × DK213 (1.26; -0.05; $0.50 \mathrm{t} /$ ha and 0.24; 0.32;-0.15 t/ha, respectively for 2013-2015), which indicates an increased moisture content of grain in them (Table 3 ). 
Table 2. Estimates of GCA effects and SCA variances in Iodent germplasm sister hybrids with respect to the "grain yield" trait in 2013-2015. t/ha.

\begin{tabular}{|c|c|c|c|c|c|c|c|}
\hline & 2013 & & 2014 & & 2015 & & \\
\hline Sister hybrids & $\begin{array}{l}\text { GCA } \\
\text { effects }\end{array}$ & $\begin{array}{l}\text { SCA } \\
\text { variances }\end{array}$ & $\begin{array}{l}\text { GCA } \\
\text { effects }\end{array}$ & $\begin{array}{l}\text { SCA } \\
\text { variances }\end{array}$ & $\begin{array}{l}\text { GCA } \\
\text { effects }\end{array}$ & $\begin{array}{l}\text { SCA } \\
\text { variances }\end{array}$ & $\begin{array}{l}\text { Sum of } \\
\text { classes }\end{array}$ \\
\hline DK1274 × DK213 & 0.101 & 0.46 & 0.002 & 0.00 & 0.641 & -0.02 & 4 \\
\hline DK1274 × DK216 & -0.323 & 0.16 & 0.132 & 0.14 & 0.222 & 0.60 & 7 \\
\hline DK1274 × DK234 & -0.112 & 0.96 & -0.263 & 0.01 & 0.112 & 0.21 & 7 \\
\hline DK1274 × DK555 & -0.483 & 0.45 & -0.032 & -0.01 & 0.092 & 0.23 & 7 \\
\hline DK213 × DK234 & -0.483 & 0.91 & -0.283 & 0.18 & 0.361 & -0.01 & 7 \\
\hline DK216 × DK213 & 0.092 & 0.16 & -0.222 & -0.02 & 0.122 & 0.18 & 6 \\
\hline DK216 × DK237 & 0.132 & 0.08 & -0.233 & 0.07 & -0.222 & 0.03 & 7 \\
\hline DK234 × DK216 & 0.481 & 0.30 & -0.222 & 0.27 & 0.351 & 0.15 & 4 \\
\hline DK237 × DK1274 & 0.102 & 0.33 & -0.022 & -0.01 & 0.072 & 0.02 & 6 \\
\hline DK237 × DK213 & 0.341 & -0.02 & 0.271 & 0.24 & 0.711 & 0.00 & 3 \\
\hline DK237 × DK234 & 0.251 & 0.33 & -0.182 & 0.03 & -0.142 & 0.65 & 5 \\
\hline DK555 × DK213 & 0.421 & 0.74 & 0.621 & 0.04 & -0.052 & 0.11 & 4 \\
\hline DK555 × DK216 & -0.303 & 0.16 & 0.241 & 0.08 & -0.353 & 0.02 & 7 \\
\hline DK555 × DK234 & -0.773 & 0.00 & -0.543 & 0.16 & -0.393 & 0.57 & 9 \\
\hline DK555 × DK237 & 0.451 & 0.18 & 0.321 & 0.57 & -0.463 & 0.46 & 5 \\
\hline DK714/195 × DK1274 & -0.182 & 0.15 & -0.483 & 0.22 & 0.341 & 0.12 & 6 \\
\hline DK714/195 × DK213 & -0.313 & 0.54 & 0.381 & 0.18 & 0.391 & 0.09 & 5 \\
\hline DK714/195 × DK216 & -0.122 & 0.03 & -0.062 & 0.04 & -0.032 & 0.23 & 6 \\
\hline DK714/195 × DK234 & 0.511 & 0.71 & 0.601 & 0.14 & -0.212 & 0.02 & 4 \\
\hline DK714/195 × DK237 & 0.411 & -0.01 & 0.062 & 0.93 & 0.162 & 0.16 & 5 \\
\hline DK714/195 × DK744 & -0.132 & 0.14 & -0.563 & 0.41 & -0.112 & 0.12 & 7 \\
\hline DK714/195 × DK555 & 0.202 & 0.46 & -0.543 & 0.12 & -0.022 & 0.22 & 7 \\
\hline DK744 × DK1274 & -0.243 & 0.08 & 0.671 & 0.19 & 0.491 & -0.02 & 5 \\
\hline DK744 × DK213 & 0.062 & 0.06 & 0.611 & 0.17 & 0.241 & 0.01 & 4 \\
\hline DK744 × DK216 & 0.361 & 0.12 & 0.152 & 0.16 & 0.052 & 0.89 & 5 \\
\hline DK744 × DK234 & -0.623 & 0.05 & 0.202 & 0.40 & 0.341 & 0.13 & 6 \\
\hline DK744 × DK237 & -0.182 & 0.29 & 0.471 & 0.43 & -0.523 & 0.14 & 6 \\
\hline DK744 × DK555 & 0.331 & 0.52 & -0.212 & 0.52 & -0.253 & 0.08 & 6 \\
\hline HIP 05 g(i) & 0.22 & - & 0.22 & - & 0.22 & - & - \\
\hline
\end{tabular}

It should be noted that some sister hybrids showed the lowest GCA estimates for this trait and had stable values over the years of studies: DK216 × DK237 (-0.48; 0.05; -0.52\%, 2013-2015. respectively),DK714/195 × DK1274 (-0.83; -0.05; $-0.22 \%)$ and DK744 × DK234 $(-0.7 ;-0.06 ;-0.03 \%)$, indicating low grain moisture content at harvest of the testcrosses obtained with their participation. For the other sister hybrids, the GCA scores varied depending on the weather conditions of the year. The SCA variances in sister hybrids had the same tendency as in the source inbred lines from which they were developed. The highest number of hybrids with high estimates of SCA variances was observed in 2013, whereas in 2014-2015, their number decreased significantly. Among the source components, the inbred lines DK744, DK555 and DK213 were the most valuable according to these parameters. The development of new precocious Iodent germplasm inbred lines was due to the expansion of the genetic basis of the new material by involving donors of precocity from related or unrelated material. That is, a large part of the precocious Iodent germplasm inbred lines contain in their genome a different proportion of unrelated genetic material. Considering that the Iodent germplasm inbred lines are more commonly used as parent components in single cross modified hybrids, it is important to determine the polymorphism of the new material to prevent complications of the hybrid structure, which increases plant variation on different grounds. 
Table 3. Assessment of GCA effects and SCA variances of Iodent germplasm sister hybrids in relation to the "grain moisture at harvest" trait in 2013-2015.\%.

2013

Sister hybrids

DK1274 × DK213

DK1274 × DK216

DK1274 × DK234

DK1274 × DK555

DK213 × DK234

DK216 × DK213

DK216 × DK237

DK234 × DK216

DK237 × DK1274

DK237 $\times$ DK213

DK237 × DK234

DK555 × DK213

DK555 × DK216

DK555 × DK234

DK555 × DK237

DK714/195 × DK1274

DK714/195 × DK213

DK714/195 × DK216

DK714/195 × DK234

DK714/195 × DK237

DK714/195 × DK744

DK744 × DK1274

DK744 × DK213

DK744 × DK216

DK744 × DK234

DK744 × DK237

DK744 × DK555

HIP $05 \mathrm{~g}(\mathrm{i})$
DK714/195 × DK555

2014

2015

$\begin{array}{lllllll}\text { GCA } & \text { SCA } & \text { GCA } & \text { SCA } & \text { GCA } & \text { SCA } & \text { classes } \\ \text { effects } & \text { variances } & \text { effects } & \text { variances } & \text { effects } & \text { variances } & \end{array}$

\begin{tabular}{|c|c|c|c|c|c|}
\hline 1,261 & 0.48 & -0.052 & -0.02 & 0.501 & 0.03 \\
\hline-0.683 & 1.55 & -0.032 & 0.00 & 0.032 & -0.01 \\
\hline 0.042 & -0.18 & -0.082 & -0.01 & 0.142 & -0.02 \\
\hline 0.332 & 0.45 & 0.162 & -0.04 & -0.202 & 0.00 \\
\hline 0.901 & 1.14 & -0.052 & -0.04 & 0.022 & 0.03 \\
\hline 0.462 & -0.21 & -0.022 & 0.03 & -0.373 & -0.02 \\
\hline-0.482 & 0.09 & 0.052 & 0.00 & -0.523 & 0.00 \\
\hline-0.152 & -0.10 & -0.283 & -0.07 & 0.072 & 0.50 \\
\hline-0.542 & 0.31 & -0.152 & -0.03 & -0.072 & -0.02 \\
\hline 0.242 & 0.24 & 0.321 & 0.35 & -0.152 & -0.01 \\
\hline 0.232 & 0.26 & -0.112 & 0.13 & 0.112 & 0.02 \\
\hline 1.181 & 0.03 & 0.142 & 0.05 & 0.172 & 0.11 \\
\hline-0.302 & 0.04 & -0.162 & -0.09 & -0.102 & 0.10 \\
\hline 0.821 & 0.54 & -0.273 & -0.09 & -0.042 & 0.15 \\
\hline 0.132 & -0.07 & -0.072 & 0.06 & -0.172 & 0.14 \\
\hline-0.833 & 0.22 & -0.052 & -0.06 & -0.222 & 0.11 \\
\hline 0.592 & 0.18 & 0.072 & 0.01 & -0.172 & 0.08 \\
\hline-0.522 & -0.09 & 0.002 & -0.01 & 0.222 & 0.15 \\
\hline 0.382 & 0.31 & 0.202 & 0.03 & 0.052 & 0.02 \\
\hline-0.452 & 1.45 & -0.172 & -0.07 & 0.192 & 0.09 \\
\hline 1.091 & -0.01 & 0.162 & -0.08 & 0.072 & 0.08 \\
\hline-0.022 & 0.14 & -0.022 & -0.08 & -0.092 & 0.15 \\
\hline-0.152 & 0.46 & -0.032 & -0.05 & 0.202 & 0.20 \\
\hline 0.162 & -0.20 & -0.112 & -0.08 & 0.032 & 0.75 \\
\hline-0.492 & -0.18 & 0.271 & 0.12 & -0.263 & 0.06 \\
\hline-0.703 & 2.21 & -0.062 & -0.09 & -0.032 & 0.09 \\
\hline 0.342 & 0.51 & 0.012 & 0.02 & -0.062 & 0.01 \\
\hline-0.132 & 1.69 & -0.062 & -0.06 & 0.172 & 0.10 \\
\hline 0.62 & - & 0.26 & - & 0.22 & - \\
\hline
\end{tabular}

It is known that the degree of similarity of the inbred lines with respect to any trait is mainly determined by the level of hypothetical heterosis in hybrids obtained from their crosses. In recent years, the index of genetic distances between breeding material has been increasingly used for the same purpose. In our studies, both methods were used, which made it possible to evaluate the inbred lines more accurately with respect to their genetic linkage. For this purpose, the obtained sister hybrids were studied for grain yield, on the basis of which the level of hypothetical heterosis was determined. Hypothetical heterosis was determined by the formula Hhypoth. = (F1-Pav. / Pav. $) \times 100 \%$, where F1 is the first-generation hybrid trait index; Pav. - its average value of parental components (Domashnev, 1992). The average grain yield of sister hybrids ranged from 6.25 to 8.03 t/ha, depending on the conditions of study years, and the variation coefficient was $14.3-17.4 \%$ with the least variability in the more stressful 2015 (Table 4). It is noteworthy that in wetter 2013 , the value of hypothetical heterosis was at the level of $85.8 \%$, due to a more complete manifestation of the level of yield in all source inbred lines and sister hybrids. It should be noted that with the averaging of hypothetical heterosis over the years, the variation of the trait increased as a result of the leveling of natural fluctuations. 
Table 4. Parameters of variation of grain yield of Iodent germplasm sister hybrids.

\section{Parameters}

$\bar{X} \pm s \bar{X}$

$\operatorname{Lim}(\min -\max )$

$\mathrm{V}, \%$

\section{Grain yield, t/ha}

2013

$8.03 \pm 0.26$

$5.83-10.17$

16.8
2014

$6.25 \pm 0.21$

$3,67-8.46$

17.4
2015

$6.91 \pm 0.19$

$5.11-8.79$

14.3

\section{$\overline{\mathbf{x}} \pm \mathbf{s} \overline{\mathbf{x}}$}

$7.07 \pm 0.22$

$4.87-9.14$

It can be argued that the level of hypothetical heterosis depends not only on the genetic distances of the breeding material, but also on its adaptability to changes in growing conditions, which can lead to errors in the estimation of the similarity level. It was found that sister hybrids with the least variable grain yields by years of research were obtained from crossing the inbred lines with the most stable manifestation of this indicator $(r=0.714)$. First and foremost, this applies to inbred lines DK1274, DK237. As for the level of hypothetical heterosis, it was almost the same over the years. Its highest value (91.7\%) was, on average, in not favorable for maize due to the weather conditions 2015 (Table 5). The presented sister hybrids were characterized by varying levels of response to the conditions of the years of study. The minimum difference between yields by years was from $0.26 \mathrm{t} / \mathrm{ha}$ (DK744 $\times$ DK555) to $1.07 \mathrm{t} / \mathrm{ha}$ (DK1274 × DK216), and the maximum $4.79 \mathrm{t} / \mathrm{ha}(\mathrm{DK} 714 / 195 \times$ DK555).

Table 5. Parameters of variation of hypothetical heterosis in Iodent germplasm sister hybrids.

\section{Parameters}

\section{Hypothetical heterosis, \%}

$\begin{array}{llll} & \mathbf{2 0 1 3} & \mathbf{2 0 1 4} & \mathbf{2 0 1 5} \\ \overline{\mathrm{X}} \pm \mathrm{s} \overline{\mathrm{X}} & 85.8 \pm 8.2 & 90.1 \pm 8.3 & 91.7 \pm 8.7 \\ \operatorname{Lim}(\min -\max ) & 19.3-184.8 & 16.3-197.9 & 36.5-176.4 \\ \mathrm{~V}, \% & 50.5 & 48.7 & 50.4\end{array}$

The maximum average yield ( $8.03 \mathrm{t} / \mathrm{ha}$ ) was recorded in 2013 , which is $23.6 \%$ more than in 2014 and $14.2 \%$ more than in 2015 . The maximum grain yield in 2013 was noted in hybrids DK714/195 × DK555 - 10.17 t/ha and DK714/195 × DK234 - 10.01 t /ha, up $2.14 \mathrm{t} / \mathrm{ha}(21.0 \%)$ and $1.98 \mathrm{t} / \mathrm{ha}(19.8 \%)$ more than its population average. The interval between the limits was about $45 \%$, indicating a different degree of manifestation of the effect of heterosis in these samples. Drought and lack of moisture at the beginning of the pollination in 2014 caused a decrease in the number of grains formed, which negatively affected the grain yield of sister hybrids. On average, it decreased by $21.6 \%$, compared to 2013 . In 2014, the minimum average yield of sister hybrids during the research years (6.25 t/ha) was observed. It should be noted that the sister hybrids: DK744 $\times$ DK1274 and DK744 $\times$ DK237 had the highest yields - $8.46 \mathrm{t} / \mathrm{ha}$ and $7.62 \mathrm{t} / \mathrm{ha}$, respectively, $2.24 \mathrm{t} / \mathrm{ha}(26.5 \%)$ and $1.40 \mathrm{t} / \mathrm{ha}(18.4 \%)$ higher than their average population value. The difference between the limits was $4.79 \mathrm{t} / \mathrm{ha}$, which is close to their values in 2013. In 2015, average grain yield of sister hybrids increased by 0.65 t/ha compared to 2014 , but was $14.2 \%$ lower than in 2013 . Its maximum level was observed in sister hybrids DK744 × DK237 and DK744 × DK1274 - 8.79 and 8.52 t/ha (20.8\% and $13.5 \%$ above average respectively). It should be noted that some sister hybrids had the highest grain yields during the years of research: DK744 $\times$ DK237 and DK744 × DK1274 showed 9.03 and 8.59 t/ ha, respectively, $22.1 \%$ and $18.2 \%$ above the population average for years of research. Yields and hypothetical heterosis were similar in years for the sister hybrids DK237 × DK213, DK237 × DK234, DK714/195 $\times$ DK237 and others. Significant fluctuations in these indicators were noted in the hybrid DK714/195 $\times$ DK555, whose parental components were characterized by low yield stability over the years. It should be noted that in the most part of the sister hybrids, the variation in grain yield and hypothetical heterosis was average, which allowed the inbred lines to be fairly accurately estimated by the level of similarity (Table 6). Grain yield analysis of sister hybrids in comparison with hypothetical heterosis indices revealed positive mean and high significant dependencies. The highest correlation was observed in 2015 ( $r=0.681)$, with the highest manifestation of hypothetical heterosis, and the lowest in $2014(r=0.498)$, with the lowest level of trait. The observed pattern proves the value of adaptability in the manifestation of the level of heterosis of sister hybrids.

A correlation analysis between the average yield of parental components and the indices of hypothetical heterosis revealed that in 2013 and 2014 the correlation between them was significantly negative ( $r=-0.785$ and -0.768 . respectively), and in 2015 - the average negative $(r=-0.490)$. The results of the studies confirm the findings (Cherchel, 2010) on the tendency of decreasing the level of hypothetical heterosis with increasing the yield of the initial components.

It is assumed that owing to breeding improvement, indices of true and hypothetical heterosis are gradually reduced, by increasing tolerance to inbreeding and the accumulation of additive components associated with yield formation while reducing the influence of specific effects (Yugenheymer, 1979). This trend may in the future transform the methods of breeding alogamous crops and bring them closer to the tools of selection of autogamous ones. Adaptability of breeding traits becomes more important than obtaining the maximum manifestation of their heterosis. Thus, the level of manifestation of hypothetical heterosis may not be a reliable indicator of the similarity of the parent components, due to the significant dependence on their productivity per se and its stability. 
Table 6. Variation of grain yield and level of hypothetical heterosis over the years in Iodent germplasm sister hybrids.

\begin{tabular}{|c|c|c|c|c|c|c|}
\hline \multirow{2}{*}{ Samples } & \multicolumn{3}{|c|}{ Grain yield, t/ha } & \multicolumn{3}{|c|}{ Hypothetical heterosis, \% } \\
\hline & 2013 & 2014 & 2015 & 2013 & 2014 & 2015 \\
\hline DK1274 × DK213 & 6.18 & 4.49 & 5.83 & 34.6 & 16.3 & 45.4 \\
\hline DK1274 × DK216 & 5.83 & 4.96 & 5.41 & 52,4 & 41.1 & 66.5 \\
\hline DK1274 × DK234 & 6.86 & 5.93 & 6.24 & 85.2 & 78.9 & 88.5 \\
\hline DK1274 × DK555 & 6.36 & 6.02 & 6.67 & 19.3 & 36.8 & 36.5 \\
\hline DK213 × DK234 & 8.17 & 7.10 & 7.29 & 119.3 & 155.9 & 134.4 \\
\hline DK216 × DK213 & 6.90 & 3,67 & 5.11 & 79.5 & 23,4 & 67.5 \\
\hline DK216 × DK237 & 9.23 & 6.18 & 8.03 & 168.7 & 103,3 & 176.4 \\
\hline DK234 × DK216 & 6.04 & 5.01 & 6.39 & 104.1 & 106.2 & 171.9 \\
\hline DK237 × DK1274 & 6.98 & 6.42 & 6.78 & 67.0 & 63,6 & 75.4 \\
\hline DK237 × DK213 & 6.52 & 6.02 & 6.15 & 55.2 & 77.8 & 67.8 \\
\hline DK237 × DK234 & 6.62 & 6.32 & 6.44 & 99.7 & 122,5 & 117.2 \\
\hline DK555 × DK213 & 7.08 & 5.20 & 6.61 & 32,3 & 34.7 & 41.1 \\
\hline DK555 × DK216 & 8.54 & 5.37 & 5.68 & 86.3 & 52,8 & 44.7 \\
\hline DK555 × DK234 & 8.49 & 5.86 & 5.65 & 90.1 & 76.8 & 41.8 \\
\hline DK555 × DK237 & 9.87 & 7.52 & 7.91 & 99.8 & 91.6 & 74.2 \\
\hline DK714/195 × DK1274 & 8.56 & 7.06 & 8.19 & 95.4 & 101.4 & 135.0 \\
\hline DK714/195 × DK213 & 8.66 & 7.04 & 8.36 & 96.8 & 137.4 & 154.5 \\
\hline DK714/195 × DK216 & 9.79 & 6.66 & 6.76 & 169.3 & 154.2 & 167.7 \\
\hline DK714/195 × DK234 & 10.01 & 7.21 & 7.04 & 184.8 & 197.9 & 172,3 \\
\hline DK714/195 × DK237 & 9.89 & 7.09 & 6.99 & 147.9 & 134.0 & 122,6 \\
\hline DK714/195 × DK744 & 7.66 & 5.99 & 6.21 & 45.1 & 85.2 & 51.5 \\
\hline DK714/195 × DK555 & 10.17 & 5.38 & 7.20 & 97.9 & 53,5 & 73,1 \\
\hline DK744 × DK1274 & 8.78 & 8.46 & 8.52 & 60.5 & 104.8 & 76.6 \\
\hline DK744 × DK213 & 7.55 & 5.34 & 6.46 & 37.5 & 48.7 & 39.7 \\
\hline DK744 × DK216 & 7.98 & 7.43 & 7.33 & 68.9 & 129.0 & 89.7 \\
\hline DK744 × DK234 & 8.77 & 6.20 & 7.91 & 90.4 & 103,6 & 101.5 \\
\hline DK744 × DK237 & 9.68 & 7.62 & 8.79 & 90.6 & 108.5 & 96.2 \\
\hline DK744 × DK555 & 7.78 & 7.52 & 7.65 & 24.9 & 82,1 & 39.1 \\
\hline Average & 8.03 & 6.25 & 6.91 & 85.8 & 90.1 & 91.7 \\
\hline
\end{tabular}

As for the genetic distances between self-pollinated lines, which are determined by SNP markers (Satarova, 2014: Lu, 2009), it is known that the smaller they are, the higher is similarity of inbreds (Kravchenko 2007: Borisova, 2014). In our studies, the average values of hypothetical heterosis indices revealed that its highest level was observed in crossing with inbred lines DK234 (137.0\%), DK714 /195 (122.7\%) and DK216 (101.1\%), and the lowest in hybrids with inbred lines DK555 (58.5\%), DK1274 (65.8\%) and DK744 (75.0\%). According to the average values of genetic distances, the studied inbred lines were characterized by a moderate polymorphism with fluctuations in genetic distances within $0.293-0.388$. and their ranking did not coincide with the distribution by the level of hypothetical heterosis. The most remote by genotype from the rest of the experimental Iodent germplasm inbred lines was sample DK714/195 (0.388), but the DK555 inbred line (0.360), which showed the lowest values of hypothetical heterosis indices, ranked second in remoteness by genetic distance. To determine the similarity of the experimental inbred lines with respect to the Iodent germplasm, we compared them with the control - the classical inbred line of this group 207 (P165) (Troyer, 1994). It should be noted that the genetic distances of sister inbred lines, as a rule, do not exceed 0.35 . and their values from 0.35 to 0.5 are characteristic of high yielding single cross hybrids (Satarova, 2014). Genetically, the Iodent germplasm is narrow enough and for its classical representatives the genetic distances do not exceed $0.15-0.20$. In our research sample, the most distant from the P165 inbred line were DK714 /195 (0.353) and DK555 (0.292), and the closest ones to it were DK744 (0.136) and DK234 (0.197). Thus, most of inbred lines can be attributed to sister ones, with the exception of DK714/195. but all of them are characterized by a considerable distance from the classical form of this germplasm, which is explained by the long selection for precocity with the involvement of unrelated sources (Table 7). It should be noted that by the genetic structure the DK714/195 inbred line is more 
related to the Mixed germplasm because it is derived from the crossing of the inbred lines Kr714 (GK26 × PLS61) (Chumak, 1999) and DK195. which was obtained from the 8 linear population of Dniprovska 12 in the structure of which there were only 2 inbred lines from the pedigree of Iodent germplasm (Gulnyashkin, 1993). However, despite its significant genetic distance from the rest of inbred lines, and on average the highest yield $(7.71 \mathrm{t} / \mathrm{ha})$ of all combinations, the presence of the hybrids with a maximum genetic distance DK714/195 × DK237 (0.423) and DK714/195 × DK555 (0.420), it did not top the sister hybrid rating by yield. The highest yields, on average, during the years of research were in the combinations DK744 $\times$ DK237 (8.70 t/ha), DK744 × DK1274 (8.59 t/ha) and DK555 × DK237 (8.43 t/ha), which did not differ in high values of genetic distances -0.309 .0 .136 . and 0.360 . respectively.

Table 7. Hypothetical heterosis in sister hybrids from crossing Iodent germplasm inbred lines and genetic distances between them.

\begin{tabular}{lllllllll}
\hline Inbred lines & DK714/195 & DK744 & DK555 & DK216 & DK213 & DK234 & DK237 & $\mathbf{2 0 7}$ \\
DK714/195 & & 0.361 & 0.420 & 0.382 & 0.385 & 0.357 & 0.423 & 0.353 \\
DK744 & 60.6 & & 0.362 & 0.292 & 0.293 & 0.139 & 0.309 & 0.136 \\
DK555 & 74.8 & 48.7 & & 0.333 & 0.313 & 0.369 & 0.360 & 0.292 \\
DK216 & 163.7 & 95.8 & 61.2 & & 0.160 & 0.322 & 0.339 & 0.257 \\
DK213 & 129.6 & 42.0 & 36.0 & 56.8 & & 0.311 & 0.337 & 0.230 \\
DK234 & 98.5 & 98.5 & 69.6 & 127.4 & 136.5 & & 0.311 & 0.197 \\
DK237 & 134.8 & 98.4 & 88.5 & 149.5 & 67.0 & 113.1 & 0.26 \\
207 & 110.6 & 80.6 & 30.9 & 53.3 & 32.1 & 84.2 & 68.7
\end{tabular}

Note. In the upper right side of the table, the data are presented by genetic distances, in the lower left - by hypothetical heterosis.

The calculations of the correlation coefficients between the level of hypothetical heterosis and genetic distances revealed no reliable correlation between them $(r=0.118-0.359)$. There is also no significant relationship between the yield of sister hybrids and genetic distances $(r=0.167-0.351)$. The alternative traits that have been identified have a different nature of formation, are characterized by continuous variation due to weather conditions and different response of genotypes to variability. Genetic distances are attributable traits, so they can only outline constant indicators. Thus, genetic distances are informative about the genetic origin and similarity of inbred lines, but predicting the explicability of quantitative indicators is much more complex, which is proven by correlation analysis.

\section{Conclusion}

The evaluation of the collection of precocious constant Iodent germplasm inbred lines by breeding traits allowed to reveal the best samples DK555 and DK1274 compared to the DK744 control. Significant impact of study years' conditions on all studied traits was noted. The study of sister hybrids revealed forms with a significant manifestation of hypothetical heterosis. It was the largest in crossings with inbred lines DK234 (137.0\%), DK714/195 (122.7\%) and DK216 (101.1\%), and the smallest in hybrids including inbred lines DK555 (58.5\%), DK1274 (65. 8\%) and DK744 (75.0\%). Sister combinations with inbred lines DK1274 and DK237 were characterized by the highest yield stability over the years of study. Determination of genetic distances between the inbred lines revealed a considerable degree of their diversity. Compared to inbred line 207 (P165), the classic representative of the Iodent germplasm, the most genetically similar to it were inbred lines DK744 (0.136) and DK234 (0.197), and the most distant ones DK714/195 (0.353) and DK555 (0.292). Comparison of the hypothetical heterosis of sister hybrids with the genetic distances between inbred lines revealed no significant relationship between these indicators. They are related to the different biological properties of the genotype and are therefore important both from a practical point of view (hypothetical heterosis) and from a theoretical one (genetic distances), which in a complex allows to correctly classify the experimental sample. Thus, the likelihood of obtaining positive results in the inbreeding of hybrids is possible only when using a comprehensive analysis of the evaluation of the GCA and the level of grain yield of testcrosses, hypothetical heterosis and genetic distances. However, the presence of a number of factors: the conditions of the year, the source material, make it difficult to clearly identify promising forms for the subsequent development of new inbred offspring.

\section{References}

Chilashvili, I. M., Suprunov, A. I., Slashchev, A. Yu. (2015). Izuchenie kombinatsionnoy sposobnosti novykh samo- opylennykh liniy kukuruzy v usloviyakh tsentral'noy zony Krasnodarskogo kraya. Zernovoe khozyaystvo Rossii. № 4 (40). S.46-50. [in Russia] Kostyuchenko, V. I. (1992). Optimizatsiya metodov identifikatsii i sinteza tsennykh genotipov pri selektsii kukuruzy na geterozis [Optimization of methods for identification and synthesis of valuable genotypes in the selection of maize for heterosis] (Doc. Agric. Sci. Diss.). Institute of Maize of Ukrainian Academy of Agrarian Sciences of, Dnipropetrovsk, Ukraine. [in Ukrainian].

Fedko, M. M. (2009). Selektsiina tsinnist samozapylenykh linii kukurudzy riznykh zarodkovykh plazm pry stvorenni hibrydiv adaptovanykh do umov zony Stepu [Selection value of self-pollinated corn lines of different embryonic plasmas in the creation of hybrids adapted to the conditions of the steppe zone] (Cand. Agric. Sci. Diss.). R\&D Institute of Grain Crops of National Academy of Agrarian Sciences of Ukraine, Dnipropetrovsk, Ukraine. [in Ukrainian] 
Haidash, O. L. (2016). Otsinka kombinatsiinoi zdatnosti za vrozhainistiu zerna samozapylenykh simei S5 kukurudzy (Zea mays L.) zmishanoi zarodkovoi plazmy. Sortovyvchennia ta okhorona prav na sorty roslyn. № 1. S. 62-66. [in Ukrainian]

Halechko I. D. (2007). Optymizatsiia elementiv rannoho testuvannia kukurudzy. Biuleten IZGH UAAN. Dnipropetrovsk. № 31-32. S. 23-26. [in Ukrainian]

Domashnev, P. P., Dzyubetskiy, B. V., Kostyuchenko, V. I. (1992). Selektsiya kukuruzy. M. Agropromizdat. - 204 s. [in Russia] Dzyubetskiy, B. V., Cherchel, V. Yu. (2002). Suchasna zarodkova plazma v programi z selektsiyi kukurudzi v Instituti zernovogo gospodarstva UAAN. Selektsiya i nasinnitstvo. HarkIv. № 86. S. 11-19. [in Ukrainian]

Dziubetskyi, B. V., Cherchel, V. Yu., Antoniuk, S. P. (2001). Selektsiia kukurudzy. Henetyka i selektsiia v Ukraini na mezhi tysiacholit: K: Lohos. Vol. 2. S. 571-589. [in Ukrainian]

Dziubetskyi, B.V., Chornomyz, A.M., Zaplitnyi, Ya.D. (2011). Vyvchennia hospodarsko - tsinnykh oznak inbrednykh linii kukurudzy zarodkovykh plazm Aiodent, Laukon ta Zmishana v umovakh zakhidnoho Lisostepu. Biuleten Instytutu Zernovoho Hospodarstva UAAN. № 1. pp. 91 - 97. [in Ukrainian]

Cherchel, V. Yu. (2018). Selektsiia skorostyhlykh hibrydiv kukurudzy, adaptovanykh do umov riznykh pryrodno-klimatychnykh zon Ukrainy [Selection of fast-growing maize hybrids, adapted to the conditions of various natural-climatic zones of Ukraine] (Doc. Agric. Sci. Diss.). DU Instytut zernovykh kultur NAAN Ukrainy. Dnipro. [in Ukrainian]

Metodyka derzhavnoho sortovyprobuvannia silskohospodarskykh kultur (zernovi, krup'yani ta zernobobovi) (2001) Pid red. Vovkodava, V. V. K. 64 s. [in Ukrainian]

Hurieva, I. A., Riabchun, V. K., Litun, P. P. (2003). Metodychni rekomendatsii polovoho ta laboratornoho vyvchennia henetychnykh resursiv kukurudzy. Kharkiv. -43 s. [in Ukrainian]

Dremlyuk, G. K., Gerasimenko, V. F. (1991). Priemy analiza kombinatsionnoy sposobnosti EVM-programy dlya neregulyarnykh skreshchivaniy. M. Agropromizdat, Odessa, SGI. - 144 s. [in Russia]

Dzyubetsky, B. V., Cherchel, V. Yu., Marochko, V. A. (2013). Formation of the sign of "humidity of corn" in fast-growing maize hybrids. Bulletin of Agrarian Science: Theoretical and Theoretical Journal. Kyiv: Agrarian Science. No. 1. P. 41-44. [in Ukrainian]

Cherchel, V. Yu., Bodenko N. A. (2010). Vrozhaynist zerna ta gipotetichniy geterozis sestrinskih gibridiv kukurudzi plazmi Reyd. Byuleten Institutu zernovogo gospodarstva. Dnipropetrovsk. № 39. S. 12-15. [in Ukrainian]

Yugenheymer, R. U.(1979) Kukuruza: uluchshenie sortov, proizvodstvo semyan, ispolzovanie. Moskva: Kolos. 519 s. [in USSR]

Satarova, T. M., Borisova, V. V., Abraimova, O. E., Cherchel, V. Yu. (2014). Analiz odnonukleotidnogo polimorfizmu DNK u liniy kukurudzi. (Metodichni aspekti). Dnipropetrovsk. $18 \mathrm{~s}$.

Lu, Y., Yan, J., Guimaräes et al, C. T. (2009). Molecular characterization of global maize breeding germplasm based on genomewide single nucleotide polymorphisms. Teor. Appl. Genet. Vol. 120. P. 93-115. [in USA]

Kravchenko, V. M. (2007). Vplyv rivnia heterozysu sestrynskykh skhreshchuvan na osnovni hospodarskotsinni oznaky modyfikovanykh hibrydiv kukurudzy [Influence of the heterosis of sister crosses on the main economic values of modified maize hybrids] (Cand. Agric. Sci. Diss.). R\&D Institute of Grain Crops of National Academy of Agrarian Sciences of Ukraine, Dnipropetrovsk. [in Ukrainian]

Borisova, V. V. (2014). Selektsiyni aspekti zastosuvannya SNP-analizu u kukurudzi [Selection aspects of the application of SNP analysis in corn] (Aft. Ref. Cand. Agric. Sci. Diss.). R\&D Institute of Grain Crops of National Academy of Agrarian Sciences of Ukraine, Dnipropetrovsk, Ukraine. [in Ukrainian]

Troyer, A. F. Breeding early corn: Ed. by Hallauer, A. R. (1994). In Specialty corns. - CBS Pres, Boca Raton. P.341-396. [in USA] Chumak, M. V. (1999) Selektsiya rannespelyih i srednespelyih gibridov kukuruzyi v Krasnodarskom NIISH. Genetika, selektsiya i tehnologiya vozdelyivaniya kukuruzyi. Maykop: RIPO Adyigeya. S. 13-28. [in Russia]

Gulnyashkin, A. V. (1993). Sozdanie liniy i gibridov kukuruzyi s byistroy poterey vlagi zernom pri sozrevanii metodom rekurrentnoy selektsii [Creation of lines and hybrids of corn with rapid loss of moisture by the grain during maturation by the method of recurrent selection] (Cand. Agric. Sci. Diss.). R\&D Institute of Grain Crops of National Academy of Agrarian Sciences of Ukraine, Dnipropetrovsk, Ukraine. [in Ukrainian]

\section{Citation:}

Dziubetskyi, B. V., Cherchel, V. Yu., Abelmasov, O. V., Semenova, V. V., Tagantsova, M. M. (2020). Iodent germplasm source material selection in development of maize hybrids for the steppe zone of Ukraine. Ukrainian Journal of Ecology, 10(1), 76-84.

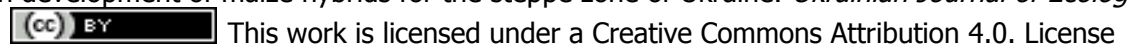

